ЕРМИЛОВ А. В., МАРДАХАЕВ Л. В., ВОЛЕНКО О. И.

ВЫДЕЛЕНИЕ ПРОФЕССИОНАЛЬНО ЗНАЧИМЫХ КАЧЕСТВ БАКАЛАВРА ТЕХНОСФЕРНОЙ БЕЗОПАСНОСТИ

РосСИЙСКИЙ пСИХОЛОГИЧЕСКИЙ ЖУРнАл, 2020, Т. 17, № 2, 73-81. doi: 10.21702/rpj.2020.2.5

пСИхолОГИЯ ТРУДА

\title{
Выделение профессионально значимых качеств бакалавра техносферной безопасности
}

\author{
Алексей В. Ермилов ${ }^{1 *}$, Лев В. Мардахаев², Ольга И. Воленко ${ }^{3}$ \\ 1 Ивановская пожарно-спасательная академия ГПС МЧС России, г. Иваново, Российская \\ Федерация \\ 2 Российский государственный социальный университет, г. Москва, Российская Федерация \\ ${ }^{3}$ Московский педагогический государственный университет, г. Москва, Российская Федерация \\ * E-mail: skash666@mail.ru \\ ORCID ID: https://orcid.org/0000-0002-0157-7712, https://orcid.org/0000-0002-9654-9246, \\ https://orcid.org/0000-0003-0065-4314
}

\begin{abstract}
Аннотация
Ввеление. Продрессиональное развитие курсантов, обучающихся по направлению полготовки 20.03.01 «Техносфрерная безопасность» (Аалее - бакалавр), во многом характеризуется сфрормированностью профрессионально значимых качеств. Основы профрессионально значимых качеств бакалавров заклалываются в вузе. Их вылеление позволяет определить ориентиры Аля поиска путей повышения качества профрессиональной поАготовки. Новизна исслеАования заключается в распределении продрессионально значимых качеств на группы в зависимости от операциональных Аействий бакалавра в ситуациях риска.

Метолы. Анализ профрессионально значимых качеств осуществлялся на основе личност-

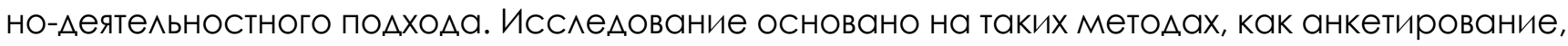
анализ психолого-педагогической и специальной ^итературы. В исслеАовании принимали участие 71 сотрудник среАнего и старшего начальствующего состава МЧС России. На первом этапе, с опорой на анализ литературы, авторами вылелены 23 продрессионально значимых качества, необхолимые бакалавру, и четыре группы их проявления. На втором этапе, на основе $а$ анных анкетирования, качества распрелелялись по группам. В кажАой группе отмечалось наиболее значимое качество.
\end{abstract}

Результаты. Аанный раздел включает характеристику вылеленных групп профрессионально значимых качеств: универсальные качества (смелость); качества, позволяющие осуществлять профрессиональную Аеятельность (быстрота оценки оперативной обстановки); качества, обеспечивающие управление ^ичным составом (^идерство); качества, позволяющие управлять собой (стрессоустойчивость).

Обсужаение результатов. Авторы рассматривают профрессионально значимые качества как ОАну из составляющих успешности осуществления Аеятельности бакалавром в среле с наличием фракторов риска. В заключении Аелается вывоА, что результаты исслеАования

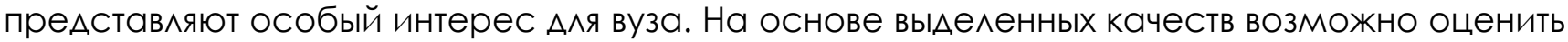
сорормированность Аичности выпускника и виАеть провалы в его поАготовке. Аанный аспект в пелагогическом процессе вуза позволяет целенаправленно созАавать специальные условия Аля проявления продрессионально значимых качеств определенной группы. 
ЕРМИЛОВ А. В., МАРДАХАЕВ Л. В., ВОЛЕНКО О. И.

ВЫДЕЛЕНИЕ ПРОФЕССИОНАЛЬНО ЗНАЧИМЫХ КАЧЕСТВ БАКАЛАВРА ТЕХНОСФЕРНОЙ БЕЗОПАСНОСТИ

РосСИйскИй психологИчЕСКИй жУРнАл, 2020, Т. 17, № 2, 73-81. doi: 10.21702/rpj.2020.2.5

ПСИхОЛОГИЯ ТРУДА

\section{КАючевые слова}

^ичность, бакалавр, профрессиональная деятельность, значимые качества, проявление качеств, фактор риска, стрессоустойчивость, смелость, быстрота, ^илерство

\section{Основные положения}

> профрессиональная Аеятельность бакалавров предъявляет повышенные требования к их профрессионально значимым качествам;

> проявление продрессионально значимых качеств бакалавров зависит от осуществления операциональных Аействий в среде с наличием фокторов риска, что позволяет объеАинить их в группы и вылелить из их числа наиболее значимые.

> технологией формирования вылеленных качеств может являться молелирование продрессиональных ситуаций, при решении которых у бакалавра обеспечивается их проявление в ситуации риска

\section{Для цитирования}

Ермилов, А. В., Мардахаев, Л. В. и Воленко, О. И. (2020). Выделение профессионально значимых качеств бакалавра техносферной безопасности. Российский психологический журнал, 17(2), 73-81. doi: 10.21702/rpj.2020.2.5

Дата получения рукописи: 08.05.2020

Дата окончания рецензирования: 27.05.2020

Дата принятия к публикации: 13.06 .2020

\section{Введение}

Результативность и оперативность профессиональной деятельности сотрудников федеральной противопожарной службы обеспечивает сохранность жизней людей и материальных ценностей государства. Как показывает практика, среди выпускников вузов МЧС России на должности, связанные с практической деятельностью, в большей степени распределяются бакалавры. Так, в 2017 году более 80 \% выпускников Ивановской пожарно-спасательной академии ГПС МЧС России были назначены на должность начальника караула, заместителя начальника и начальника пожарно-спасательной части. Существенная особенность данных должностей заключается в обеспечении караульной службы в пожарно-спасательной части и выполнении основной боевой задачи на месте вызова.

При ликвидации чрезвычайной ситуации личный состав подвергается чрезмерной физической, психологической и психоэмоциональной нагрузке (Човдырова, 2016). На личность бакалавра оказывает влияние необходимость осуществления деятельности в ночное время суток, в непригодной для дыхания среде с учетом условий и ограничений временных ресурсов (Гринченко и Тараканов, 2018). При решении профессиональных ситуаций бакалавр обязан проявлять разумный риск и быть ответственным за подчиненный личный состав при отдаче распоряжений (Мардахаев, 2015; Карпов и Карпов, 2016).

Анализ специальной литературы позволил сделать вывод, что основными операциональными действиями бакалавра являются:

- принятие решений и обеспечение их выполнения; 
ЕРМИЛОВ А. В., МАРДАХАЕВ Л. В., ВОЛЕНКО О. И.

ВЫДЕЛЕНИЕ ПРОФЕССИОНАЛЬНО ЗНАЧИМЫХ КАЧЕСТВ БАКАЛАВРА ТЕХНОСФЕРНОЙ БЕЗОПАСНОСТИ

РосСИЙСКИЙ пСИХОЛОГИЧЕСКИЙ ЖУРнАл, 2020, Т. 17, № 2, 73-81. doi: 10.21702/rpj.2020.2.5

ПСИХОЛОГИЯ ТРУДА

- включение в деятельность с сохранением управленческих функций;

- осуществление профессиональной деятельности согласно должностным обязанностям, взаимодействуя с номерами расчета;

- оперативная оценка ситуации и произведение анализа вариантов возможных действий с учетом тактических возможностей подразделения;

- обеспечение надежности выполнения поставленных задач в ситуациях профессионального риска вплоть до жертвования собственной жизнью.

Выделенные операциональные действия осуществляются в экстремальной среде, которая характеризуются внезапностью, масштабностью чрезвычайной ситуации и длительностью влияния факторов риска на личность. За счет отсутствия у бакалавра необходимого опыта, недостаточного понимания им профессиональной ситуации в целом, недостаточной психологической подготовленности и низкого уровня эмоциональной устойчивости нарушается процесс выполнения профессиональной деятельности. Одним из основных факторов невыполнения поставленной задачи является возникновение у бакалавра стресса (Стрельникова, 2015). В стрессовой ситуации у недостаточно подготовленного человека возникают такие психические состояния, как сильное возбуждение, кратковременный или длительный ступор, проявляющийся в неподвижности и молчании (Шевченко и Макарова, 2016). Растерянность приводит к затруднению анализа поступающей информации, реализации неверных действий и искажению оценки временных интервалов. Это приводит к снижению эффективности, ошибкам, срывам, росту вероятности получения травмы и невыполнения поставленной задачи (Стрельникова, 2015; Жуйкова, 2015; Шипилов, Шарабанова, Зейнетдинова и Кокурин, 2017). Также важно отметить, что длительность ликвидации чрезвычайной ситуации требует постоянной мобилизации личностных ресурсов организма.

Следовательно, успешное осуществление бакалавром операциональных действий в ситуациях с наличием фактора риска зависит от ряда условий:

1) обеспеченности бакалавра информацией о профессиональной ситуации, надежности пожарных автомобилей, пожарно-технических средств и личного состава;

2) развитых профессиональных навыков, умений и качеств личности, поддерживающих работоспособность человека при решении задач в нетипичных условиях профессиональной деятельности (Шойгу и Тарасова, 2017; Hansen, Netteland, \& Wasson, 2016).

На основе данного вывода определена цель исследования.

Цель исследования: выделить профессионально значимые качества, необходимые бакалавру техносферной безопасности, распределить их по группам в зависимости от обеспечения операциональных действий в ситуациях риска.

\section{Методы}

\section{Организация исследования}

Организация исследования осуществлялась в 2016 году. В качестве экспертов выступал профессорско-преподавательский состав Ивановской пожарно-спасательной академии, а также средний и старший начальствующий состав Ивановского местного пожарно-спасательного гарнизона. Общая численность экспертной группы составляла 71 человек.

Исследование проводилось в два этапа. На первом этапе составлена общая совокупность профессионально значимых качеств, необходимых бакалавру для обеспечения выполнения профессиональной деятельности, а также выделены основные группы их проявления. На втором 
ЕРМИЛОВ А. В., МАРДАХАЕВ Л. В., ВОЛЕНКО О. И.

ВЫДЕЛЕНИЕ ПРОФЕССИОНАЛЬНО ЗНАЧИМЫХ КАЧЕСТВ БАКАЛАВРА ТЕХНОСФЕРНОЙ БЕЗОПАСНОСТИ

РосСИйскиЙ психологИчЕСКИй жУРнАл, 2020, Т. 17, № 2, 73-81. doi: 10.21702/rpj.2020.2.5

ПСИхолОгИЯ тРУДА

этапе выделенные профессионально значимые качества распределялись по группам на основе экспертных оценок. В каждой группе выделялось наиболее значимое качество.

\section{Методы исследования}

Исследование осуществлялось в рамках личностно-деятельностного подхода, который учитывает индивидуальные особенности каждого человека (Кожунов, 2016). Личностная сторона данного подхода обеспечивает выполнение бакалавром поставленных задач в профессиональной среде. Деятельностная сторона готовит бакалавров к самореализации при выполнении задач по профессиональному назначению. Опираясь на данный подход, выделены профессионально значимые качества и их проявление при выполнении бакалавром поставленных задач в среде с наличием ситуаций риска.

Выделение профессионально значимых качеств и разделение их на группы осуществлялось в процессе теоретического анализа исследований, психолого-педагогической и специальной литературы. Для распределения качеств по группам разработана анкета. Разработанная анкета представляет собой таблицу. Головная строка таблицы содержит группы проявления профессионально значимых качеств, а ее левая часть - их перечень. Анкетирование заключалось в отметке экспертами неограниченного количества качеств, необходимых для каждой группы их проявления. Также в каждой группе экспертам предлагалось отдельно выделить одно наиболее значимое качество.

\section{Результаты}

Анализ специальной литературы позволил выявить тесную взаимосвязь понятий «профессионально важные качества» и «профессионально значимые качества» (Душков, Королев и Смирнов, 2005, с. 471). Проблема понятия «профессионально важные (значимые) качества» изначально раскрыта в специальной литературе и исследованиях по военной психологии. Военными психологами подчеркивается, что для решения задач военно-профессиональной деятельности, обучения и воспитания у военнослужащих должны быть сформированы волевые черты характера, а также ценностные ориентации, мотивы, установки и физические качества (Марищук, 1982; Барабанщиков и Феденко, 1981, с. 90).

Данный аспект позволил выделить 23 профессионально значимых качества, необходимых бакалавру: быстрота оценки оперативной обстановки; быстрота принятия решений в условиях отвлекающих воздействий и дефицита времени; быстрота реакции на неожиданное слуховое впечатление посредством определенных действий; верность профессиональному долгу; взаимовыручка; дисциплинированность (управляемость); коллективизм; лидерство; находчивость; ответственность в сложных ситуациях; профессиональная наблюдательность; решительность; самоотверженность; самооценка; самостоятельность; смелость; сообразительность; стрессоустойчивость; требовательность; уверенность в своих силах и способностях; физическая выносливость и устойчивость к физической усталости; целеустремленность в условиях отвлекающих трудностей; эмоциональная устойчивость.

Изложенный материал, а также характер профессиональной деятельности сотрудника федеральной противопожарной службы позволили выделить группы профессионально значимых качеств и дать им качественную характеристику (табл. 1). 
ЕРМИЛОВ А. В., МАРДАХАЕВ Л. В., ВОЛЕНКО О. И.

ВЫДЕЛЕНИЕ ПРОФЕССИОНАЛЬНО ЗНАЧИМЫХ КАЧЕСТВ БАКАЛАВРА ТЕХНОСФЕРНОЙ БЕЗОПАСНОСТИ

РосСИЙСКИЙ пСИХОЛОГИЧЕСКИЙ ЖУРнАл, 2020, Т. 17, № 2, 73-81. doi: 10.21702/rpj.2020.2.5

ПСИхОЛОГИЯ ТРУДА

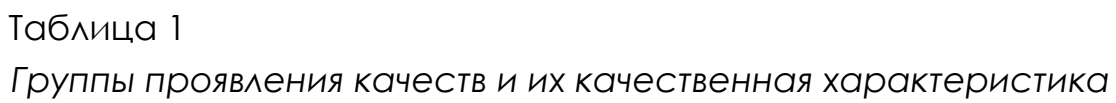

Результаты анкетирования сотрудников позволили распределить профессионально значимые качества по группам. Результаты представлены в таблице 2.

\section{Таблица 2}

Распределение проорессионально значимых качеств бакалавра по группам

№ группы

1) Аисциплинированность (управляемость);

2) ответственность в сложных ситуациях;

3) целеустремленность в условиях отвлекающих трудностей;

4) находчивость;

1

5) уверенность в своих силах и способностях;

6) быстрота реакции на неожиланное слуховое впечатление посреАством опреАеленных Аействий;

7) смелость 
ЕРМИЛОВ А. В., МАРДАХАЕВ Л. В., ВОЛЕНКО О. И.

ВЫДЕЛЕНИЕ ПРОФЕССИОНАЛЬНО ЗНАЧИМЫХ КАЧЕСТВ БАКАЛАВРА ТЕХНОСФЕРНОЙ БЕЗОПАСНОСТИ

РосСиЙский психологИчЕСКИй жУРнАл, 2020, Т. 17, № 2, 73-81. doi: 10.21702/rpj.2020.2.5

пСИхолОГИЯ ТРУДА

Таблица 2

Распрелеление профрессионально значимых качеств бакалавра по группам

№rруппы $\quad$ Продрессионально значимые качества

1) быстрота оценки оперативной обстановки; 24

2) профрессиональная наблюАательность; 12

3) сообразительность; 9,3

2 4) самостоятельность; $\quad 6,7$

5) фризическая выносливость и устойчивость к ффизической усталости; $\quad 18,7$

6) взаимовыручка; 14,7

7) комлективизм 14,7

$\begin{array}{ll}\text { 1) АиАерство; } & 46,7\end{array}$

2) быстрота принятия решений в условиях отвлекающих возАействий и лефицита времени;

3) требовательность

1) верность профессиональному Аолгу; 9,3

2) решительность; 16

3) самоотверженность; 5,3

4

4) эмоциональная устойчивость; 29,3

5) стрессоустойчивость; $\quad 38,7$

6) самооценка 1,3

Таким образом, в каждой группе выделены качества, позволяющие всесторонне охарактеризовать сформированность личности бакалавра в процессе обучения. К данным качествам относятся: смелость (30,7\%), быстрота оценки оперативной обстановки (24\%), лидерство (46,7\%), стрессоустойчивость (38,7\%).

\section{Обсуждение результатов}

Анализ специальной литературы и результаты исследования позволили уточнить понятие «профессионально значимые качества бакалавра МЧС России». Под данным определением понимаются качества, определяющие способность и готовность бакалавра выполнять деятельность по профессиональному назначению при ликвидации сложившейся чрезвычайной ситуации, обеспечивая управление личным составом и собой в ситуации риска, проявляя верность профессиональному долгу, решительность и самоотверженность.

Результаты экспериментальной работы подтверждаются исследованиями в специальной литературе. Так, эффективность осуществления деятельности тесно взаимосвязана 
ЕРМИЛОВ А. В., МАРДАХАЕВ Л. В., ВОЛЕНКО О. И.

ВЫДЕЛЕНИЕ ПРОФЕССИОНАЛЬНО ЗНАЧИМЫХ КАЧЕСТВ БАКАЛАВРА ТЕХНОСФЕРНОЙ БЕЗОПАСНОСТИ

РосСИЙСКИЙ пСИХОЛОГИЧЕСКИЙ ЖУРнАл, 2020, Т. 17, № 2, 73-81. doi: 10.21702/rpj.2020.2.5

ПСИхОЛОГИЯ ТРУДА

с стрессоустойчивостью, смелостью и решительностью (Власкина, 2013). Стрессоустойчивость обеспечивает адаптацию человека в экстремальных условиях, позволяя им переносить физические, интеллектуальные, волевые и эмоциональные нагрузки (Шевченко и Макарова, 2016; Жуйкова, 2015). За счет смелости личность преодолевает страх перед реальной или воображаемой опасностью. Решительность оказывает влияние на быстроту выбора и принятия решений, а также выполнение последующих действий (Глазунов и Сидоров, 2016). Лидерство обеспечивает собственное Я в сознании человека и является совокупностью социально-коммуникативных и социально-психологических средств обеспечения организованности социальных общностей (Лозова, 2017; Мартенс, 2018). Показателями сформированности выделенных профессионально значимых качеств являются умения бакалавра - выбирать и принимать управленческие решения, прогнозировать свои дальнейшие действия, анализировать обстановку, а также осуществлять операциональные действия на уровне номера и командира пожарного расчета.

\section{Заключение}

Авторы статьи не подменяют понимание о сущности профессионально значимых качеств курсантов-бакалавров, а дополняют ее в разделе подготовки в вузах МЧС России.

Распределение профессионально значимых качеств на группы позволит осуществлять оценку профессионального становления личности бакалавра в вузах МЧС России и обеспечить ее корректировку в рамках целенаправленного педагогического процесса (Sizikova, Anikeeva, Galkina, Mardakhaev, Starovojtova, \& Makarov, 2015; Egorychev, Mardahaev, Rybakova, Fomina, \& Sizikova, 2014; Мардахаев и Макаренко, 2015; Романов, 2015; Irkhina, Irkhin, Davydenko, Shehovskaya, \& Krolevetskaya, 2016; Isaeva, Mamatova, Kovalenko, \& Kurganskiy, 2016; Levanova, Sleptsova, Khripunkova, \& Mazkina, 2018). Для обеспечения данного аспекта необходимо, чтобы подготовка в вузах дополнялась развитием личностных качеств за счет мотивации к саморазвитию (Мигунова, 2016). Важно подчеркнуть, что особое внимание необходимо уделять интеллектуальной, волевой, эмоциональной и физической сферам личности (Цилик, 2015). При этом профессорско-преподавательский и командный состав обязан непрерывно совершенствовать выделенные профессионально значимые качества бакалавра через оперативные образы типичных и нетипичных ситуаций (Аникеева, 2013). Достижение данной цели обуславливает необходимость применения моделирования профессиональных ситуаций, которые будут способствовать возникновению динамики эмоциональных состояний, обеспечивая развитие у личности способности к саморегуляции (Васильев, 2017; Попова, 2018).

\section{Литература}

Аникеева, Н. В. (2013). Значение волевых качеств личности в профессиональном становлении. Вестник Московского университета МВД России, 5, 242-245.

Барабанщиков, А. В. и Феденко, Н. Ф. (ред.) (1981). Основы военной психологии и педагогики: Учебное пособие. Москва: Воениздат.

Васильев, Б. Ю. (2017). Методы формирования морально-волевых качеств у курсантов военных вузов. Профессиональное образование в России и за рубежом, 1 (25), 77-83.

Власкина, И. В. (2013). Корреляции профессионально важных качеств и эффективности профессиональной деятельности работников сферы «человек - человек». Образование и наука, 3 (102), 75-87. 
ЕРМИЛОВ А. В., МАРДАХАЕВ Л. В., ВОЛЕНКО О. И.

ВЫДЕЛЕНИЕ ПРОФЕССИОНАЛЬНО ЗНАЧИМЫХ КАЧЕСТВ БАКАЛАВРА ТЕХНОСФЕРНОЙ БЕЗОПАСНОСТИ

РосСИйский психологИчЕСКИй жУРнАл, 2020, Т. 17, № 2, 73-81. doi: 10.21702/rpj.2020.2.5

пСИхолОГИЯ ТРУДА

Глазунов, Ю. Т. и Сидоров, К. Р. (2016). Семейства психологических свойств независимых волевых качеств. Вестник Удмуртского университета. Серия Философия. Психология. Педагогика, 26(4), 50-59.

Гринченко, Б. Б. и Тараканов, Д. В. (2018). Модель управления безопасностью при работах на пожарах в непригодной для дыхания среде. Пожаровзрывобезопасность / Fire and Explosion Safety, 27(6), 45-51.

Душков, Б. А., Королев, А. В. и Смирнов, Б. А. (2005). Психология труда, профессиональной, информационной и организационной деятельности: Словарь. Москва: Академический Проект: Фонд «Мир».

Жуйкова, И. В. (2015). Стрессоустойчивость как профессионально-важное качество сотрудников противопожарной службы. Перспективы науки, 3 (66), 21-24.

Карпов, А. В. и Карпов, А. А. (2016). Процессы принятия решения в структурной организации деятельности. Российский психологический журнал, 13(2), 132-155. doi: 10.21702/rpj.2016.2.11

Кожунов, К. А. (2016). Личностно-деятельностный подход в формировании патриотизма и гражданственности у курсантов военного вуза. Вестник Челябинского государственного педагогического университета, 5, 71-76.

Лозова, О. (2017). Психосемантика лідерства у буденній свідомості студентів. Педагогічний прочес: теорія і практика, 3 (58), 60-65. doi: 10.28925/2078-1687.2017.3.6065

Мардахаев, Л. В. (2015). Нравственные основы личности современного офицера. Вестник академии военных наук, 4 (53), 53-58.

Мардахаев, Л. В. и Макаренко, В. С. (2015). Социокультурная среда военного вуза в формировании активной позиции защитника Отечества. Ученые записки Российского государственного социального университета, 14(4), 126-132. doi: 10.17922/2071-5323-2015-14-4-126-132

Марищук, В. Л. (1982). Психологчческие основы формирования профессионально значимых качеств (докторская диссертация). Ленинградский ордена Ленина и Трудового Красного Знамени государственный университет им. А. А. Жданова. Военный дважды Краснознаменный институт физической культуры, Ленинград.

Мартенс, О. К. (2018). Сущность и природа лидерства. Вестник Московского государственного областного университета. Серия: Философские науки, 1, 76-84. doi: 10.18384/2310-7227-2018-1-76-84

Мигунова, Ю. С. (2016). Закономерности влияния мотивационной сферы командиров младшего звена на направленность межличностных отношений. Российский психологический журнал, 13(3), 312-327. doi: 10.21702/rрj.2016.3.18

Попова, С. И. (2018). Технология регулирования эмоциональных состояний учащегося. Российский психологический журнал, 15(1), 187-204. doi: 10.21702/rpj.2018.1.9

Романов, Д. А. (2015). Процессуальные модели становления личностно-профессиональных качеств. Научные труды Кубанского государственного технологического университета, 3, 176-199.

Стрельникова, Ю. Ю. (2015). Психологическая коррекция посттравматических симптомов и изменений личности у сотрудников МЧС России, принимавших участие в ликвидации последствий чрезвычайных ситуаций. Вестник Южно-Уральского государственного университета. Серия: Психология, 8(2), 25-33.

Цилик, В. А. (2015). Оценка профессионально-личностных качеств сотрудников ОВД в зависимости от вида профессиональной деятельности. Психопедагогика в правоохранительных органах, 3 (62), 113-116. 
ЕРМИЛОВ А. В., МАРДАХАЕВ Л. В., ВОЛЕНКО О. И.

ВЫДЕЛЕНИЕ ПРОФЕССИОНАЛЬНО ЗНАЧИМЫХ КАЧЕСТВ БАКАЛАВРА ТЕХНОСФЕРНОЙ БЕЗОПАСНОСТИ

РосСИЙСКИЙ пСИХОЛОГИЧЕСКИЙ ЖУРнАл, 2020, Т. 17, № 2, 73-81. doi: 10.21702/rpj.2020.2.5

ПСИхОЛОГИЯ ТРУДА

Човдырова, Г. С. (2016). Психологические профессионально важные качества оперативных сотрудников различных направлений деятельности системы МВД России. Вестник Московского университета МВД России, 6, 197-204.

Шевченко, Т. И. и Макарова, Н. В. (2016). Динамика копинг-поведения пожарных в процессе профессиональной деятельности. Вестник МАНЭБ, 21(1), 65-74.

Шипилов, Р. М., Шарабанова, И. Ю., Зейнетдинова, О. Г. и Кокурин, А. К. (2017). Особенности адаптации курсантов образовательных организаций высшего образования к действиям в условиях чрезвычайных ситуаций. В мире научных открытий, 9(1), 78-89. doi: 10.12731/ wsd-2017-1-78-89

Шойгу, Ю. С. и Тарасова, А. А. (2017). Выделение профессионально важных качеств инспектора Государственной инспекции по маломерным судам МЧС России. Российский психологический журнал, 14(4), 267-295. doi: 10.21702/rpj.2017.4.13

Egorychev, A. M., Mardahaev, L. V., Rybakova, A. I., Fomina, S. N., \& Sizikova, V. V. (2014). Society and education in the early of $X X I^{\text {th }}$ century: Integration of tradition and innovation. Journal of Advanced Research in Law and Economics, 5(2), 82-91.

Hansen, C., Netteland, G., \& Wasson, B. (2016). Learning analytics and open learning modelling for professional competence development of firefighters and future healthcare leaders. CEUR Workshop Proceedings, 1601, 87-90.

Irkhina, I. V., Irkhin, V. N., Davydenko, T. M., Shehovskaya, N. L., \& Krolevetskaya, E. N. (2016). Technology of didactic system development management of the teacher under professional activity conditions. The Social Sciences (Pakistan), 11(10), 2479-2482. doi: 10.3923/ sscience.2016.2479.2482

Isaeva, N. I., Mamatova, S. I., Kovalenko, V. I., \& Kurganskiy, S. I. (2016). The study on the professional culture as a system-making competence of the future specialist. The Social Sciences (Pakistan), 11(4), 529-534. doi: 10.3923/sscience.2016.529.534

Levanova, E. A., Sleptsova, M. V., Khripunkova, O. V., \& Mazkina, O. B. (2018). Pedagogical functions within the educational process, Espacios, 39(43), 22.

Sizikova, V. V., Anikeeva, O. A., Galkina, T. A., Mardakhaev, L. V., Starovojtova, L. I., \& Makarov, V. E. (2015). Experimental study of the possibilities of professional activity standardization in the social work: Russian experience. Biosciences Biotechnology Research Asia, 12(1), 895-901. doi: 10.13005/ $\underline{\mathrm{bbra} / 1737}$

Конфликт интересов отсутствует 